13,03

\title{
Сравнительный анализ толщины и электрической проводимости тонких халькогенидных полупроводниковых пленок
}

\author{
(C) В.В. Даньшина, Л.Ф. Калистратова \\ Омский государственный технический университет, \\ Омск, Россия \\ E-mail: danshina_v@mail.ru \\ (Поступила в Редакцию 11 мая 2016 г.)
}

\begin{abstract}
Проведено рентгенографическое исследование структуры и толщины полупроводниковых пленок халькогенидов цинка и кадмия. Показано, что толщина пленок соизмерима с глубиной половинного слоя ослабления рентгеновских лучей. При нагревании в атмосфере водорода электрическая проводимость пленок увеличивается, а при нагревании в оксиде углерода уменьшается. Получена противоположная тенденция в соотношении величин электрической проводимости и ширины запрещенной зоны исходной и окисленной поверхностей пленок.
\end{abstract}

DOI: 10.21883/FTT.2017.01.43970.174

\section{1. Введение}

Полупроводниковые пленки имеют широкое применение в области радиотехнической аппаратуры: в оптоэлектронных устройствах записи информации, для создания светодиодов с синим излучением, полупроводниковых лазеров, солнечных батарей и элементов систем лазерного телевидения. Параметры и характеристики приборов измерительной техники (например, термоэлектрических измерительных устройств) улучшаются после нанесения пленки на поверхности преобразователей. Поэтому при изготовлении пленочных преобразователей большое значение имеет технология получения как пленок с исходным составом, так и пленок определенной толщины. Пленки наносятся разными способами: термическим испарением в вакууме, катодным распылением, электронно-лучевым испарением, мгновенным (взрывным) испарением, химическим и электролитическим осаждением и др. Пленки халькогенидных полупроводников получаются преимущественно первыми тремя способами [1].

Халькогениды цинка и особенно кадмия нашли широкомасштабное наземное применение в тонкопленочных солнечных элементах (СЭ) [2,3] благодаря максимальному среди полупроводниковых материалов теоретическому коэффициенту полезного действия (свыше 29\% для $\mathrm{CdTe}$ и $17 \%$ для $\mathrm{CdSe}$ ). Считается, что это обусловлено большими значениями ширины запрещенной зоны (свыше $1 \mathrm{eV}$ ), оптимальными для фотоэлектрического преобразования солнечного излучения в наземных условиях. При эксплуатации пленочных СЭ на основе халькогенидов кадмия в наземных условиях на их поверхности происходит адсорбция газов - компонентов воздуха. В результате этого могут измениться рабочие характеристики СЭ. Поэтому всегда актуальными являются исследования как электрофизических свойств тонких полупроводниковых пленок, так и влияния адсорбированных газов на эти свойства.
Цель настоящей работы заключается в анализе влияния теплового воздействия и воздействия газовой среды при различных давлениях на электрическую проводимость тонких халькогенидных пленок кадмия и цинка.

\section{2. Объекты и методика эксперимента}

Полупроводниковые пленки халькогенидов цинка $(\mathrm{ZnSe}, \mathrm{ZnTe})$ и кадмия (CdSe, CdTe) были получены в установке вакуумного поста ВУП-4К в режиме динамического вакуума при давлении $0.133 \mathrm{mPa}$ с помощью термического испарения при температуре конденсации $298 \mathrm{~K}$ предварительно очищенных поликристаллических образцов $(T=653 \mathrm{~K})$ на подложки двух типов (керамика и германий) без дополнительного подогрева подложек. При нагревании халькогениды цинка и кадмия могут разделяться на отдельные компоненты, которые испаряются с разными скоростями. Поэтому очень важно контролировать состав и толщину данных пленочных покрытий.

Аттестация пленочных образцов проводилась на основе расшифровки рентгенограмм, полученных от исследуемых образцов на рентгеновской установке ДРОН-3 в $\mathrm{Cu}$-фильтрованном излучении в области углов дифракции $2 \theta=10-90^{\circ}$. Расчет параметров кристаллической решетки фазовых составляющих производился по стандартным формулам анализа структуры рентгенографическим методом [4].

Толщина полупроводниковых пленок оценивалась по трем разным методикам: по глубине проникновения световых лучей в интерферометре марки ИЗК-452 (метод 1); исходя из условий напыления (метод 2) по формуле

$$
d=\frac{m \sin \varphi}{4 \pi R^{2} \rho},
$$

где $m-$ масса образца, $\varphi-$ угол испарения, $R-$ расстояние от испарителя до подложки, $\rho-$ табличная 
плотность соединения. Метод 3 заключался в расчете глубины половинного слоя ослабления рентгеновских лучей по формуле, представленной в [2]:

$$
t=\frac{0.69 \sin \theta}{2 \mu}
$$

где $\theta-$ угол дифракции, $\mu-$ линейный коэффициент поглощения рентгеновских лучей веществом, вычисляемый на основе массовых коэффициентов поглощения компонентов соединения и его плотности,

$$
\frac{\mu}{\rho}=\sum_{i=1}^{n}\left(\frac{\mu}{\rho}\right) i .
$$

При расчетах по формуле (3) использовались значения рентгеновской плотности вещества, вычисляемые на основе знаний о параметрах кристаллической ячейки:

$$
\rho=\frac{n M}{k V_{0} N_{A}}
$$

где $M$ - молярная масса соединения, $n-$ число атомов, приходящихся на элементарную ячейку, $k-$ одинаковое число атомов в химической формуле соединения, $V_{0}-$ объем элементарной ячейки, $N_{A}$ - число Авогадро.

Электрическая проводимость пленок измерялась двухзондовым методом на постоянном токе в вакууме и в атмосфере газовых сред: водорода $\left(\mathrm{H}_{2}\right)$ и оксида углерода (II) (CO). Перед измерениями образцы вакуумировались при давлении $\sim 0.13 \mathrm{mPa}$ и температуpe $643 \mathrm{~K}$. Длительность отжига и эксперимента при каждой температуре определялась по получению постоянных значений поверхностной проводимости. Относительные погрешности вычисления параметров кристаллической ячейки составляют $2 \%$, температуры - $5 \%$, электрической проводимости $-2 \%$.

\section{3. Результаты эксперимента и их обсуждение}

Анализ обработки рентгенограмм показал, что для всех соединений получено хорошее согласие экспериментальных и табличных межплоскостных расстояний $d / n$. В качестве примера для пленки $\mathrm{CdSe}$ представлена штрих-диаграмма с индексами отражающих

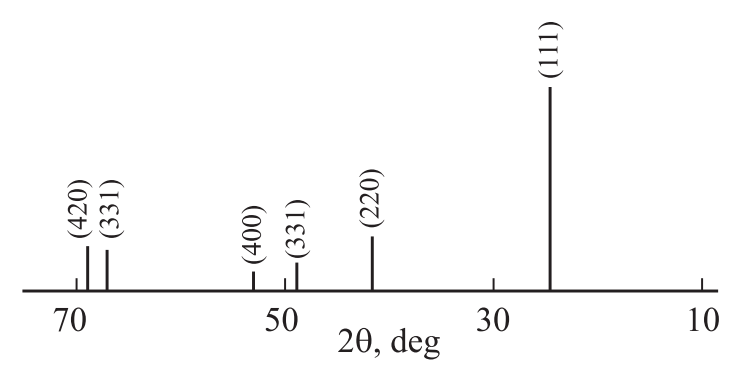

Рис. 1. Штрих-диаграмма пленки CdSe.
Таблица 1. Значения межплоскостных расстояний $d / n$ для пленки $\mathrm{CdSe}$

\begin{tabular}{c|c|c|c|c|c}
\hline \multirow{2}{*}{$\begin{array}{c}\text { № } \\
\text { п/п }\end{array}$} & \multirow{2}{*}{$2 \theta$} & $\theta$ & \multirow{2}{*}{$\begin{array}{c}(d / n)_{\exp }, \\
\mathrm{nm}\end{array}$} & \multicolumn{2}{|c}{ Табличные значения } \\
\cline { 5 - 6 } & & & & $d / n, \mathrm{~nm}$ & $h k l$ \\
\hline 1 & $25^{\circ} 35^{\prime}$ & $12^{\circ} 47^{\prime}$ & 0.348 & 0.349 & $(111)$ \\
2 & $42^{\circ} 10^{\prime}$ & $21^{\circ} 05^{\prime}$ & 0.214 & 0.214 & $(220)$ \\
3 & $49^{\circ} 50^{\prime}$ & $24^{\circ} 55^{\prime}$ & 0.183 & 0.182 & $(311)$ \\
4 & $52^{\circ} 40^{\prime}$ & $26^{\circ} 20^{\prime}$ & 0.174 & 0.175 & $(400)$ \\
5 & $67^{\circ} 50^{\prime}$ & $33^{\circ} 55^{\prime}$ & 0.138 & 0.139 & $(331)$ \\
6 & $69^{\circ} 20^{\prime}$ & $34^{\circ} 40^{\prime}$ & 0.135 & 0.135 & $(420)$
\end{tabular}

Таблица 2. Плотность и толщина пленок

\begin{tabular}{c|c|c|c|c|c}
\hline Пленка & $\begin{array}{c}\rho_{\text {tabl }}, \\
\mathrm{g} / \mathrm{cm}^{3}\end{array}$ & $\begin{array}{c}\rho_{x \text {-ray }} \\
\mathrm{g} / \mathrm{cm}^{3}\end{array}$ & $\begin{array}{c}d_{\text {method } 2,}, \\
\mu \mathrm{m}\end{array}$ & $\begin{array}{c}\mu, \\
\mathrm{cm}^{-1}\end{array}$ & $\begin{array}{c}t, \\
\mu \mathrm{m}\end{array}$ \\
\hline $\mathrm{CdSe}$ & 5.81 & 5.77 & 2.8 & 920 & 1.9 \\
$\mathrm{ZnSe}$ & 5.27 & 5.28 & 2.6 & 373 & 4.6 \\
$\mathrm{CdTe}$ & 6.34 & 6.30 & 2.8 & 1103 & 1.6
\end{tabular}

плоскостей после вычета рефлексов подложки (рис. 1) и проведено сравнение значений табличных и экспериментальных межплоскостных расстояний $d / n$ (табл. 1).

Рентгенографические исследования показали,что применяемый нами способ напыления пленок приводит к созданию однородной поликристаллической структуры, соответствующей халькогенидным химическим соединениям. Рассчитанные параметры кристаллической решетки для всех исследуемых соединений совпадают с табличными значениями кубической элементарной ячейки $K$ 4: $a=0.605,0.566$ и $0.608 \mathrm{~nm}$ для $\mathrm{CdSe}, \mathrm{ZnSe}$, $\mathrm{ZnTe} \mathrm{соответственно.}$

Толщина пленок $d$, оценка которой проводилась по методу 1 , оказалась в пределах $1-5 \mu \mathrm{m}$, при оценке по методу 2 при табличной величине плотности материала $\rho$ она составила не более $3 \mu \mathrm{m}$ (табл. 2).

Значения рентгеновской плотности вещества $\rho_{x \text {-ray }}$, вычисленные на основе параметров кристаллической ячейки, практически совпадают с табличными (табл. 2). Глубина половинного слоя ослабления рентгеновских лучей $(t)$, участвовавшего в образовании дифракционной картины, была вычислена для угла дифракции $\theta=30^{\circ}$ (середина дифракционной картины). Для соединения $\mathrm{ZnSe}$ за счет малого коэффициента ослабления рентгеновских лучей $\mu$ глубина слоя ослабления рентгеновских лучей примерно в 2 раза больше таковой, чем для других изучаемых соединений (табл. 2). Кроме того, величины $t$ находятся в хорошем согласии с величинами толщин пленок, измеренными с помощью первых двух методов (табл. 2). Таким образом, можно констатировать, что толщина полученных халькогенидных пленок составляет не более $3 \mu \mathrm{m}$. Следует отметить, что единой классификации пленок по толщине до сих пор не существует. Так, при толщине свыше $10 \mathrm{~nm}$ их считают просто „тонкими“, а в области толщин 
Таблица 3. Значения электрической проводимости халькогенидов кадмия в вакууме при различных температурах

\begin{tabular}{c|c|c}
\hline$T, \mathrm{~K}$ & $n$-CdSe & $\begin{array}{c}p \text {-CdTe } \\
\sigma \cdot 10^{5}, \mathrm{~S}\end{array}$ \\
\hline 313 & $0 \cdot 10^{3}, \mathrm{~S}$ & 0.8 \\
333 & 0.55 & 1.6 \\
353 & 1.30 & 2.6 \\
373 & 1.65 & 4.2 \\
393 & 2.00 & 5.9 \\
413 & 2.35 & 7.8 \\
433 & 4.75 & 9.4
\end{tabular}

Таблица 4. Значения электрической проводимости окисленного $n$-CdSe при различных температурах

\begin{tabular}{c|c|c|c}
\hline \multirow{2}{*}{$T, \mathrm{~K}$} & \multicolumn{3}{|c}{$\sigma \cdot 10^{5}, \mathrm{~S}$} \\
\cline { 2 - 4 } & Водород & Вакуум & Оксид углерода (II) \\
\hline 373 & 0 & 0.1 & 0.1 \\
393 & 0.3 & 0.5 & 0.6 \\
413 & 0.8 & 1.1 & 1.2 \\
423 & 1.1 & 1.4 & 1.7 \\
433 & 1.6 & 2.0 & 2.3 \\
553 & 2.5 & 3.0 & 3.4
\end{tabular}

порядка нескольких микрометров - субмикронными [5]. На основании этого мы предполагаем, что исследуемые нами пленки халькогенидных соединений действительно можно отнести к „тонким“ (косвенно на это указывает наличие на рентгенограммах рефлексов материала подложек). В связи с этим замечанием результаты наших исследований, касающихся электрической проводимости, будем относить именно к поверхностной проводимости. Следует сразу отметить, что значения поверхностной проводимости пленок могут отличаться от объемной проводимости [5].

Электрическая проводимость $\sigma$ для исходных халькогенидных пленок с примесной проводимостью определялась в температурном интервале $293-433$ K в вакууме, а также в атмосфере водорода и оксида углерода (II) при различных давлениях газовой среды. Теоретически температурная зависимость проводимости примесных полупроводников сложная: имеет три неравнозначные области. В так называемой низкотемпературной области (I) проводимость создается примесными атомами, степень ионизации которых увеличивается при возрастании температуры. При достижении некоторой температуры все примесные атомы становятся ионизованными и не могут поставлять носители тока: наступает область истощения примесей (область II). Затем при дальнейшем нагревании проводимость полупроводника снова увеличивается (область III) за счет собственных носителей тока. В этой области температур примесный полупроводник ведет себя как собственный. Рассматриваемые халькогенидные соединения с примесной проводимостью относятся к полупроводникам с большим значением ширины запрещенной зоны. Так, для соединения $n$-CdSe табличное значение ширины запрешенной зоны $\Delta E=1.74 \mathrm{eV}$, для $p$-CdTe $\Delta E=1.56 \mathrm{eV}$.

Отметим,что область температур 293-433 К для изучаемых примесных халькогенидных полупроводников является низкотемпературной областью I. Проводимость пленок здесь возрастает при увеличении температуры по экспоненциальному закону, что соответствует теоретическим представлениям. Для примера в табл. 3 приведены значения электрической проводимости халькогенидов кадмия в вакууме при различных температурах. Проводимость акцепторного полупроводника ( $p$-CdTe) на два порядка ниже, чем для донорного (n-CdSe).

При воздействии на поверхность тонких пленок жидких и газовых сред могут происходить изменения различных свойств, в том числе и электрофизических. Так, при адсорбции молекул газов часто происходит изменение электрического заряда поверхности, от которого зависит концентрация заряда в приповерхностной области полупроводника,называемой областью пространственного заряда. Влияние вида и давления газовых сред на электрическую проводимость исследуемых пленок можно проследить на примере $n$-CdSe, температурные зависимости которого приведены на рис. 2. В атмосфере водорода электрическая проводимость всех пленок увеличивается (положительное заряжение поверхности), а в оксиде углерода (II) падает (отрицательное заряжение).

Для выяснения влияния оксидной пленки на заряжение поверхности при адсорбции газов на халькогенидных полупроводниках была измерена электрическая проводимость окисленных в атмосфере кислорода при температуре выше $673 \mathrm{~K}$ пленочных образцов (табл. 4). Оказалось, что проводимость окисленных соединений на

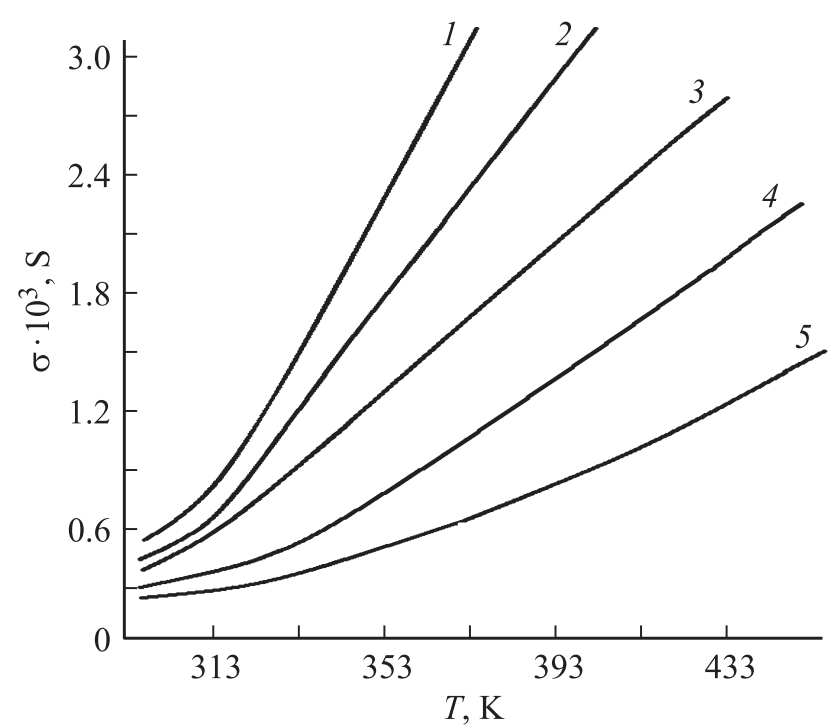

Рис. 2. Температурная зависимость электрической проводимости $n$-CdSe. 1 - водород $(27.9 \mathrm{~Pa}), 2$ - водород $(9.9 \mathrm{~Pa})$, 3 - вакуум, 4 - оксид углерода $(9.7 \mathrm{~Pa}), 5$ - оксид углерода $(27.9 \mathrm{~Pa})$. 
Таблица 5. Ширина энергетических интервалов соединений в разных средах при различном давлении

\begin{tabular}{l|c|c|c}
\hline \multirow{2}{*}{ Среда } & \multicolumn{3}{|c}{$\Delta E_{0}, \mathrm{eV}$} \\
\cline { 2 - 4 } & $n$-CdSe & $p$-CdTe & $\begin{array}{c}n \text {-CdSe } \\
\text { (окисленный) }\end{array}$ \\
\hline Вакуум & 0.33 & 0.46 & 0.61 \\
$\mathrm{CO}, 4 \mathrm{~Pa}$ & 0.31 & 0.48 & - \\
$\mathrm{CO}, 30 \mathrm{~Pa}$ & 0.36 & 0.53 & 0.56 \\
$\mathrm{H}_{2}, 4 \mathrm{~Pa}$ & 0.39 & 0.52 & - \\
$\mathrm{H}_{2}, 30 \mathrm{~Pa}$ & 0.43 & 0.54 & 0.66
\end{tabular}

2-3 порядка ниже, чем для исходных. При этом адсорбция водорода уменьшает, а оксида углерода увеличивает электрическую проводимость образца по сравнению с вакуумом.

На основе полулогарифмических прямых температурных зависимостей $\ln \sigma=f(1 / / T)$ были вычислены значения ширины энергетического интервала $\left(\Delta E_{0}\right)$ между донорными уровнями и зоной проводимости для $n$-полупроводников (соответственно между валентной зоной и акцепторными уровнями для $p$-полупроводников): $\Delta E_{0}=2 k \operatorname{tg} \alpha$ (табл. 5).

Величина энергетического интервала $\Delta E_{0}$ оказалась для $p$-халькогенидных соединений больше, чем для $n$-соединений. В работе [6] показано, что в результате воздействия на поверхность полупроводниковых пленок различными жидкими средами изменяется ширина запрещенной зоны $\Delta E$ в пленке $\mathrm{CdTe}$, а без воздействия она практически равна табличной величине [7]. В нашем исследовании происходит изменение ширины энергетического интервала $\Delta E_{0}$ при воздействии газовых сред (табл. 5): для $n$-CdSe при давлении газовых сред $30 \mathrm{~Pa}$ в атмосфере оксида углерода (II) она увеличивается на $18 \%$, а в атмосфере водорода - на $30 \%$. Для соединения $p$-CdTe аналогичные значения составляют 13 и $17 \%$ соответственно. В окисленных пленках проявляется другая тенденция в изменении величин $\Delta E_{0}$ после адсорбции газов (табл. 5). Во-первых, значения величин $\Delta E_{0}$ окисленной пленки больше в среднем в 2 раза, чем для исходной поверхности в вакууме, а вовторых, адсорбция водорода на ней увеличивает ширину энергетического интервала на $8 \%$, а оксида углерода уменьшает ее на $8 \%$.

\section{4. Заключение}

Таким образом, наши исследования показали, что в условиях адсорбции газов на поверхности халькогенидов цинка и кадмия наблюдается несовпадение величин электропроводности, характера заряжения поверхности и значений ширины энергетической зоны между примесными уровнями и уровнями основных зон полупроводника. На исходной поверхности пленок имеет место соотношение $\sigma_{\mathrm{CO}}<\sigma_{\text {vacuum }}<\sigma_{\text {hydrogen }}$, свидетельствующее о том, что оксид углерода (II) заряжает поверхность отрицательно, а водород - положительно. Поскольку в атмосфере промышленного мегаполиса концентрация углерода (II) часто превышает предельно допустимую, для эффективной работы солнечных элементов в реальных условиях необходимо защищать от его вредного воздействия.

При длительной эксплуатации пленок в реальных условиях влажности воздуха происходит их окисление, а затем старение. Это изменяет характер исходного состояния заряжения на противоположный по сравнению с поведением в вакууме. Окисление приводит к изменению концентрации заряда в приповерхностной области полупроводника: на окисленной поверхности пленок наблюдается соотношение $\sigma_{\text {hydrogen }}<\sigma_{\text {vacuum }}<\sigma_{\mathrm{CO}}$, указывающее на то, что водород заряжает поверхность отрицательно, а оксид углерода (II) - положительно. Это свидетельствует о неодинаковой природе активных центров, различных механизмах взаимодействия газов с поверхностью и соответственно о том, что присутствующая на реальной поверхности полупроводников оксидная фаза не является центром адсорбции.

Отметим еще один результат: впервые проведена оценка толщины пленок рентгенографическим способом.

\section{Список литературы}

[1] А.В. Волков. Компьютерная оптика 24, 74 (2002).

[2] N. Ali, A. Hussain, R. Ahmed, M.K. Wang, C. Zhao, B.U. Haq, Y.Q. Fu. Renew. Sustain. Energy Rev. B 59, 726 (2016).

[3] I. Lokteva, N. Radichev, F. Witt, H. Borchert, J. Parisi. J. Phys. Chem. 114, 12784 (2010).

[4] Л.И. Миркин. Справочник по рентгеноструктурному анализу поликристаллов. Физматгиз. М. (1961). 863 с.

[5] Е.А. Москатов. Основы электронной техники. Феникс, Ростов н/Д (2010). 378 с.

[6] B. Maniscalco, A. Abbas, J.W. Bowers, P.M. Kaminski, K. Bass, G. West, J.M. Walls. Thin Solid Films 582, 115 (2015).

[7] В.В. Брус, М.Н. Солован, Э.В. Майструк, И.П. Козярский, П.Д. Марьянчук, К.С. Ульяницкий, J. Rappich. ФТТ 56, 1886 (2014). 